\title{
EFEITO IN VITRO E IN VIVO DE EXTRATOS DE Eugenia uniflora EM NEMATÓDEOS GASTRINTESTINAIS DE OVINOS
}

\section{IN VITRO AND IN VIVO EFFECT OF Eugenia uniflora EXTRACTS ON GASTROINTESTINAL NEMATODE OF SHEEP}

\author{
Luciana Laitano Dias de Castro ${ }^{1 *}$ ORCID - http://orcid.org/0000-0002-9173-3650 \\ Lew Kan Sprenger ${ }^{2}$ ORCID - http://orcid.org/0000-0003-4236-9837 \\ Isabel Martins Madrid1 ORCID - http://orcid.org/0000-0002-9886-6050 \\ Fernando Caetano de Oliveira1 ORCID - http://orcid.org/0000-0002-5191-9901 \\ Plíno Aguiar de Oliveira1 ORCID - http://orcid.org/0000-0002-9326-5299 \\ Leonardo Mortagua de Castro ${ }^{1}$ ORCID - http://orcid.org/0000-0002-5705-6748 \\ Maria Elisabeth Aires Berne1 ORCID - http://orcid.org/0000-0003-4444-1134 \\ Fábio Pereira Leivas Leite ${ }^{1}$ ORCID - http://orcid.org/0000-0003-0941-7286 \\ ${ }^{1}$ Universidade Federal de Pelotas, Pelotas, RS, Brasil. \\ ${ }^{2}$ Faculdades Integradas do Vale do Iguaçu, União da Vitória, PR, Brasil. \\ *Autora para correspondência - lu.Idcastro@gmail.com
}

\section{Resumo}

Este estudo avaliou a ação in vitro e in vivo de extratos de Eugenia uniflora em nematódeos gastrintestinais de ovinos. No teste de inibição da eclodibilidade dos ovos, extratos aquosos e hidroalcoólicos foram testados nas concentrações de 40 a $1,25 \mathrm{mg} / \mathrm{mL}$. O efeito citotóxico foi mensurado através do ensaio de MTT em células VERO nas concentrações de 4000 a 1,95 $\mu \mathrm{g} / \mathrm{mL}$. A composição química foi analisada através da marcha fitoquímica qualitativa. No teste in vivo, foram administrados $100 \mathrm{mg} / \mathrm{kg}$, por via oral, do extrato hidroalcoólico por três dias em ovinos naturalmente infectados e realizada coleta de fezes para estimar a redução de ovos por grama de fezes (OPG). Diferentes extratos de E. uniflora inibiram a eclodibilidade dos ovos, com percentual de inibição variando de 14,56 a $99,75 \%$, sendo os hidroalcoólicos mais promissores que os aquosos. Na marcha fitoquímica, compostos com ação anti-helmíntica comprovada foram observados, como flavonoides, saponinas, taninos e triterpenos. Nas condições testadas, os extratos apresentaram citotoxicidade nula a moderada. In vivo, a redução do OPG foi observada apenas no grupo controle (anti-helmíntico). Os extratos de E. uniflora mostraram-se promissores com ação in vitro, necessitando estudos que avaliem outras concentrações e formas de administração in vivo.

Palavras-chave: planta medicinal; Haemonchus contortus; ruminantes; anti-helmíntico; pitangueira.

\begin{abstract}
:
This study evaluated the in vitro and in vivo action of Eugenia uniflora extracts on sheep gastrointestinal nematode. In the egg hatchability inhibition assay, aqueous and hydroalcoholic extracts were tested in the concentrations ranging from 40 to $1.25 \mathrm{mg} / \mathrm{mL}$. The cytotoxic effect was measured using the MTT assay on VERO cells at concentrations ranging from 4000 to $1.95 \mu \mathrm{g} / \mathrm{mL}$. The chemical composition was analyzed through the qualitative phytochemical screening. In the in vivo test, $100 \mathrm{mg} / \mathrm{kg}$ of the hydroalcoholic extract was administered orally for three days in sheep naturally infected and fecal collection was performed to estimate the egg count per gram of faeces (EPG). Different extracts of $E$.
\end{abstract}


uniflora inhibited hatchability of eggs with a percentage of inhibition ranging from 14.56 to $99.75 \%$, being the hydroalcoholic most effective than the aqueous. In phytochemical analysis, compounds with anthelmintic action were observed, such as flavonoids, saponins, tannins and triterpenes. Extracts showed moderate to null cytotoxicity under the conditions tested. Reduction of EPG was observed only in control group (anthelmintic). The extracts of $E$. uniflora proved promising with in vitro action, requiring studies that assess other concentrations and forms of in vivo administration.

Keywords: medicinal plants; Haemonchus contortus; ruminants; anthelmintic; Brazilian cherry.

Recebido em: 28 de Agosto de 2017

Aceito em 09 de julho de 2018.

\section{Introdução}

A produção brasileira de pequenos ruminantes tem grande importância econômica, gerando renda a milhares de pequenos e médios produtores. Contudo, o manejo sanitário incorreto é o principal entrave para a saúde e o bem-estar desses animais ${ }^{(1)}$. A infecção por Haemonchus contortus é a principal doença parasitária nacional, causando anorexia, apatia, aumento da conversão alimentar, comprometimento da função reprodutiva e perda de peso em animais infectados ${ }^{(2)}$.

A principal medida de controle adotada para minimizar as perdas geradas pelos nematódeos é a utilização de anti-helmínticos, porém, o uso abusivo e errôneo desses fármacos acelerou o desenvolvimento de parasitos resistentes a essas drogas ${ }^{(3)}$. Estudos afirmam que esse problema se encontra em diferentes regiões do Brasil $^{(4)}$ e também é disseminado mundialmente ${ }^{(5,6)}$. Além disso, os riscos decorrentes de resíduos de anti-helmínticos ou seus metabólitos em alimentos derivados de animais reforçam a necessidade da descoberta de compostos ativos seguros e acessíveis através das plantas $^{(7)}$. Para solucionar esse problema, muitas tecnologias estão sendo desenvolvidas, sendo que a fitoterapia tem demonstrado bons resultados ${ }^{(8)}$. O Brasil possui a mais diversa flora do mundo, e o uso desses medicamentos está amplamente difundido na população ${ }^{(9)}$.

Eugenia uniflora (Myrtaceae) é uma árvore tropical e subtropical amplamente distribuída nos países sul-americanos, principalmente Brasil, Argentina, Uruguai e Paraguai ${ }^{(10)}$. As suas folhas são utilizadas na medicina popular na forma de infusão para o tratamento de febre, reumatismo, distúrbios gástricos e hipertensão ${ }^{(11)}$. Outros estudos relatam que a planta tem propriedades anti-inflamatórias, antifúngicas e anti-helmíntica ${ }^{(12,13)}$. Ao avaliarem a ação in vitro no desenvolvimento de larvas de nematódeos gastrintestinais de ovinos, Hassum e colaboradores ${ }^{(13)}$ observaram efeito do extrato hidroalcoólico de E. uniflora na redução desse desenvolvimento, tendo uma baixa contagem de larvas infectantes quando comparado ao grupo controle. Devido aos escassos estudos, o objetivo do presente trabalho foi avaliar a ação anti-helmíntica in vitro, através do teste de inibição da eclodibilidade, e in vivo de diferentes extratos de Eugenia uniflora em face de nematódeos gastrintestinais de ovinos.

\section{Material e métodos}

O estudo foi aprovado pelo Comitê de Ética em Experimentação Animal da Universidade Federal de Pelotas (CEEA 3897). 
Folhas frescas da planta Eugenia uniflora (pitangueira) foram coletadas na zona rural de Canguçu, Rio Grande do Sul, Brasil, em dezembro de 2012. E. uniflora foi identificada pela Prof. ${ }^{a}$ Raquel Lüdtke e depositada no acervo do Herbário PEL, Departamento de Botânica da Universidade Federal de Pelotas, sob o número voucher 25.872. A planta foi desidratada em estufa com circulação de ar a $35^{\circ} \mathrm{C}$, por três dias. As folhas secas foram trituradas e estocadas em frascos fechados e protegidos da luz até o momento da produção dos extratos.

A partir das folhas secas da planta, foram produzidos dois extratos aquosos e três hidroalcoólicos utilizando como solvente álcool de cereais $70^{\circ} \mathrm{GL}$, sempre na concentração de $10 \%$. Após a metodologia, todos os extratos foram liofilizados e armazenados a $20^{\circ} \mathrm{C}$ negativos.

O extrato aquoso por decocção (EA/DEC) foi preparado a partir da ebulição da planta em água destilada a $100^{\circ} \mathrm{C}$ em frasco fechado por 10 minutos. Após, a amostra foi filtrada para eliminação de resíduos sólidos e congelada a $-75^{\circ} \mathrm{C}$. Para produção do extrato aquoso em banho-maria (EA/BM), a solução permaneceu sob agitação constante em frasco fechado imerso em óleo na temperatura de $65^{\circ} \mathrm{C}$ por uma hora. Após este período, o material foi filtrado e o mesmo procedimento repetido por mais duas vezes com a mesma planta, as três partidas foram congeladas a $-75^{\circ} \mathrm{C}$.

O extrato hidroalcoólico em banho-maria (EHA/BM) foi produzido através da mesma metodologia citada para o EA/BM, porém, antes de o material ser congelado, o solvente foi extraído em evaporador rotativo a $55^{\circ} \mathrm{C}$ sob $600 \mathrm{~mm} / \mathrm{hg}$ de pressão negativa. Para a produção do extrato hidroalcoólico por ultrassom (EHA/US), a extração foi realizada em sonicador com frequência de $500 \mathrm{kHz}$ e amplitude de $40 \%$ por 15 minutos em temperatura ambiente. Após este período, o material permaneceu $24 \mathrm{~h}$ sob refrigeração a $4^{\circ} \mathrm{C}$ e posteriormente foi filtrado, o solvente evaporado e congelado a $-75^{\circ} \mathrm{C}$. O extrato hidroalcoólico por maceração (EHA/MA) foi preparado a partir de uma tintura que permaneceu em maceração sob agitação diária por sete dias em temperatura ambiente. Após este período, a solução foi filtrada, o solvente extraído em evaporador rotativo e o extrato mantido a $-75^{\circ} \mathrm{C}$.

A marcha fitoquímica qualitativa de todos os extratos foi realizada conforme protocolo descrito por $\operatorname{Matos}^{(14)}$, com o objetivo de verificar a presença de metabólitos secundários (antraquinonas, catequinas, esteróis, fenóis, flavonoides, resinas, saponinas, taninos, triterpenos).

O efeito citotóxico dos extratos foi avaliado através do ensaio de MTT (brometo tiazoli azul de tetrazólio), descrito por Mosmann ${ }^{(15)}$ com modificações. Células VERO foram cultivadas em RPMI 1640 suplementado com soro fetal bovino $10 \%$, em uma atmosfera com $5 \%$ de $\mathrm{CO}_{2}$ a $37^{\circ} \mathrm{C}$. Uma suspensão de células contendo $2 \times 10^{5} \mathrm{cel} / \mathrm{mL}$ foi semeada em microplacas de 96 poços e incubada por 24h nas condições citadas acima. Posteriormente, $100 \mu \mathrm{L}$ de cada extrato em 12 concentrações sucessivas de 4000 a $1,95 \mu \mathrm{g} / \mathrm{mL}$ foram adicionados à microplaca, a qual permaneceu por $48 \mathrm{~h}$ a $37^{\circ} \mathrm{C}$ em atmosfera de $5 \%$ de $\mathrm{CO}_{2}$. O teste foi acompanhado por controle de crescimento celular, utilizando RPMI 1640, e cada concentração dos extratos foi testada em triplicata. Após este período, $50 \mu \mathrm{L}$ de MTT $(2,5 \mathrm{mg} / \mathrm{mL})$ foram adicionados a cada poço e incubados durante duas horas e trinta minutos, posteriormente foram removidos e $50 \mu \mathrm{L}$ de DMSO (dimetilsulfóxido) foram acrescidos sob agitação durante cinco minutos para solubilizar os cristais de formazan formados pelas células viáveis que metabolizaram o MTT. A absorbância das amostras foi mensurada através de espectrofotômetro de microplaca em comprimento de onda de $540 \mathrm{~nm}$. Os resultados foram expressos através do percentual de células viáveis relativa às células do controle (considerado como 100\%).

Os ovos foram obtidos através da coleta de fezes diretamente da ampola retal de dois ovinos naturalmente infectados por nematódeos gastrintestinais (NGI). Os animais foram mantidos sem tratamento anti-helmíntico por no mínimo 60 dias antes da coleta e com a contagem de ovos por grama 
de fezes (OPG), realizada pela técnica de Gordon e Whitlock ${ }^{(16)}$, acima de 2000. Para a recuperação dos ovos, foi utilizada a técnica de Hubert e Kerboeuf ${ }^{(17)}$ adaptada, sendo as fezes maceradas, diluídas em água destilada e passadas através de quatro tamises, dispostas em ordem decrescente de abertura de malha $(1 \mathrm{~mm} ; 105 \mu \mathrm{m} ; 55 \mu \mathrm{m} ; 25 \mu \mathrm{m})$. Os ovos foram recuperados do tamis de $25 \mu \mathrm{m}$, lavados através de centrifugações, diluídos em água destilada e quantificados em triplicata. $\mathrm{O}$ gênero das larvas dos nematódeos presentes nas fezes foi determinado através da técnica de coprocultura descrita por Roberts e O`Sullivan ${ }^{(18)}$.

O teste foi realizado em placa de microcultivo de 24 poços com quatro repetições, segundo a técnica de Coles $^{(19)}$. Em cada poço foi colocado aproximadamente 150 ovos e o extrato a ser testado em seis concentrações sucessivas de 40 a $1,25 \mathrm{mg} / \mathrm{ml}$. Como controles, foram utilizados tiabendazol na concentração de $0,025 \mathrm{mg} / \mathrm{ml}$ e água destilada estéril. As placas foram incubadas em estufa B.O.D a $28^{\circ} \mathrm{C}$ com umidade relativa de $80 \%$ por $24 \mathrm{~h}$ para a posterior quantificação de ovos e larvas de primeiro estádio em microscópio invertido. Os resultados foram expressos pela média percentual da inibição da eclodibilidade da quadruplicata, sendo a eficácia de cada tratamento no teste de eclosão determinada conforme a equação descrita por Camurça-Vasconcelos ${ }^{(20)}$ : $\%$ de inibição da eclodibilidade $=$ [número de larvas (número de larvas + número de ovos)-1]100.

Foram utilizados 24 ovinos da raça corriedale, com 8 a 10 meses de idade, de ambos os sexos, naturalmente infectados por nematódeos gastrintestinais e divididos em grupos de oito animais cada um. Os animais estavam no mínimo há 60 dias sem receber tratamento anti-helmíntico e foram distribuídos homogeneamente nos grupos conforme a carga parasitária estimada pela contagem de OPG. Durante o período experimental, os animais permaneceram em pastagem nativa recebendo água ad libitum. O grupo controle positivo recebeu anti-helmíntico comercial (moxidectina, via subcutânea, $0,2 \mathrm{mg} / \mathrm{kg}$ ) e o controle negativo água. Para o grupo tratamento, o extrato hidroalcoólico por maceração de E. uniflora (EHA/MA) na concentração de $100 \mathrm{mg} / \mathrm{Kg}$ foi administrado diariamente, por via oral, durante três dias consecutivos. Para avaliar a eficácia do tratamento, foi realizada a coleta individual de fezes diretamente da ampola retal nos dias $0,3,7,10$ e 14 após o início do tratamento para a contagem de OPG e coprocultura. Para a determinação do percentual de redução do OPG, utilizou-se a fórmula descrita por Coles ${ }^{(19)}: \%$ Redução $=(1-[$ Dia pós tratamento/Dia zero] 100.

Os resultados dos testes de citotoxicidade, de inibição da eclodibilidade e do teste in vivo foram analisados utilizando ANOVA e as médias comparadas através do teste de Tukey $(p \leq 0,05)$, usando o software Statistix ${ }^{\circledR}$ 9.0. Para a análise dos dados do teste in vivo, os resultados foram normalizados através da transformação por $\log 10$.

\section{Resultados}

Os resultados da marcha fitoquímica qualitativa estão descritos na Tabela 1, sendo que foram semelhantes aos observados em estudo desenvolvido com óleo essencial de E $_{\text {. }}$ unflora $^{(21)}$. Verificando a composição fitoquímica dos extratos, observou-se diferença entre a composição dos extratos aquosos em relação aos extratos hidroalcoólicos, sendo que os extrato EHA/BM e EHA/MA demonstraram maior quantidade de compostos, com relação aos demais pesquisados.

No teste de citotoxicidade, os diferentes extratos testados apresentaram graus variáveis de toxicidade em células VERO de acordo com a concentração, apresentando um efeito dose-dependente positivo. Ao analisar os diferentes extratos dentro da mesma concentração, observou-se que a ação tóxica não apresentou diferença acentuada na maioria das concentrações, sendo que para todos os extratos o 
percentual de células viáveis variou de 51,23 a 100\% (Tabela 2).

Tabela 1. Resultados da marcha fitoquímica qualitativa dos diferentes extratos produzidos com Eugenia uniflora

\begin{tabular}{cccccc}
\hline Testes realizados & EA/DEC & EA/BM & EHA/BM & EHA/US & EHA/MA \\
\hline Antraquinonas & - & - & + & + & + \\
Catequinas & + & + & + & + & + \\
Esteróis & - & - & + & - & + \\
Fenóis & + & + & + & + & + \\
Flavonoides & - & - & + & - & + \\
Resinas & - & + & + & + & + \\
Saponinas & + & + & + & + & + \\
Taninos & + & + & + & + & + \\
Triterpenos & - & - & + & - & + \\
\hline
\end{tabular}

EA/DEC - extrato aquoso por decocção; EA/BM - extrato aquoso em banho-maria; EHA/BM - extrato hidroalcoólico em banho-maria; EHA/US - extrato hidroalcoólico por ultrassom; EHA/MA - extrato hidroalcoólico por maceração.

Tabela 2. Média percentual de células viáveis tratadas com extratos de Eugenia uniflora em diferentes concentrações

\begin{tabular}{cccccc}
\hline $\begin{array}{c}\text { Concentrações } \\
(\boldsymbol{\mu} \mathbf{g} / \mathbf{m L})\end{array}$ & $\mathbf{5}$ Extratos \\
\cline { 2 - 6 } & $\mathbf{E A} / \mathbf{D E C}$ & $\mathbf{E A} / \mathbf{B M}$ & $\mathbf{E H A} / \mathbf{B M}$ & $\mathbf{E H A} / \mathbf{U S}$ & $\mathbf{E H A} / \mathbf{M A}$ \\
\hline 4000 & $60,39^{\mathrm{A}}$ & $51,23^{\mathrm{A}}$ & $55,62^{\mathrm{A}}$ & $51,35^{\mathrm{A}}$ & $57,96^{\mathrm{A}}$ \\
2000 & $67,03^{\mathrm{A}}$ & $52,28^{\mathrm{C}}$ & $55,88^{\mathrm{BC}}$ & $62,59^{\mathrm{AB}}$ & $63,28^{\mathrm{AB}}$ \\
1000 & $71,78^{\mathrm{A}}$ & $66,27^{\mathrm{AB}}$ & $59,63^{\mathrm{B}}$ & $72,45^{\mathrm{A}}$ & $64,98^{\mathrm{AB}}$ \\
500 & $78,38^{\mathrm{AB}}$ & $71,09^{\mathrm{BC}}$ & $60,61^{\mathrm{C}}$ & $87,97^{\mathrm{A}}$ & $65,68^{\mathrm{C}}$ \\
250 & $82,86^{\mathrm{AB}}$ & $72,34^{\mathrm{C}}$ & $75,99^{\mathrm{BC}}$ & $90,29^{\mathrm{A}}$ & $72,07^{\mathrm{C}}$ \\
125 & $87,22^{\mathrm{AB}}$ & $82,96^{\mathrm{BC}}$ & $81,76^{\mathrm{BC}}$ & $92,65^{\mathrm{A}}$ & $74,88^{\mathrm{C}}$ \\
62,50 & $88,52^{\mathrm{AB}}$ & $92,82^{\mathrm{A}}$ & $87,66^{\mathrm{AB}}$ & $93,77^{\mathrm{A}}$ & $76,54^{\mathrm{B}}$ \\
31,25 & $96,46^{\mathrm{A}}$ & $93,01^{\mathrm{A}}$ & $89,56^{\mathrm{A}}$ & $95,48^{\mathrm{A}}$ & $78,57^{\mathrm{A}}$ \\
15,63 & $98,97^{\mathrm{A}}$ & $98,41^{\mathrm{A}}$ & $99,99^{\mathrm{A}}$ & $98,97^{\mathrm{A}}$ & $87,18^{\mathrm{A}}$ \\
7,81 & $100^{\mathrm{A}}$ & $100^{\mathrm{A}}$ & $100^{\mathrm{A}}$ & $99,99^{\mathrm{A}}$ & $90,46^{\mathrm{B}}$ \\
3,90 & $99,99^{\mathrm{A}}$ & $100^{\mathrm{A}}$ & $100^{\mathrm{A}}$ & $100^{\mathrm{A}}$ & $96,33^{\mathrm{A}}$ \\
1,95 & $99,99^{\mathrm{A}}$ & $100^{\mathrm{A}}$ & $100^{\mathrm{A}}$ & $100^{\mathrm{A}}$ & $98,44^{\mathrm{A}}$ \\
\hline
\end{tabular}

$\mathrm{EA} / \mathrm{DEC}$ - extrato aquoso por decoç̧ão; EA/BM - extrato aquoso em banho-maria; EHA/BM - extrato hidroalcoólico em banho-maria; EHA/US - extrato hidroalcoólico por ultrassom; EHA/MA - extrato hidroalcoólico por maceração.

Letras maiúsculas diferentes, na linha, diferem significativamente entre si $(\mathrm{p} \leq 0.05)$.

No teste in vitro de inibição da eclodibilidade, os diferentes extratos de E. uniflora apresentaram ação anti-helmíntica sobre NGI de ovinos com percentual médio de inibição entre 14,56 e 76,04\% para os extratos aquosos (Figura 1) e de 20,35 a 99,75\% para os hidroalcoólicos (Tabela 3). Na maior concentração testada $(40 \mathrm{mg} / \mathrm{mL})$, verificou-se diferença estatística na atividade ovicida entre os extratos aquosos e hidroalcoólicos, os quais apresentaram média de $99 \%$ de inibição da eclodibilidade $(\mathrm{p} \leq 0,05)$. Os controles com água destilada e anti-helmíntico demonstraram inibição de 8,91 e 98,58\%, 
respectivamente. O resultado das coproculturas revelou a presença dos gêneros Haemonchus (97\%) e Trichostrongylus (3\%).

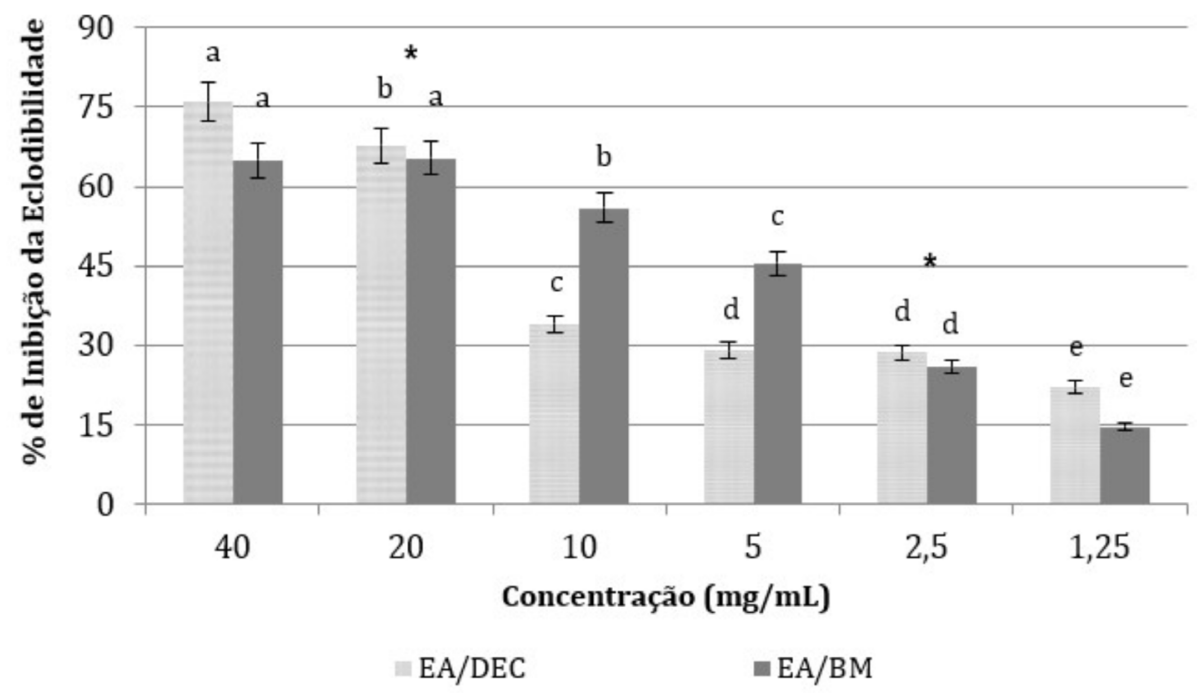

Figura 1. Percentual médio de inibição da eclodibilidade de nematódeos gastrintestinais de ovinos ( \pm desvio-padrão) pelos extratos aquosos por decocção (EA/DEC) e por banho-maria (EA/BM) de Eugenia uniflora.

Letras minúsculas entre as concentrações do mesmo extrato diferem estatisticamente $(p \leq 0,05)$. * indica as concentrações em que os extratos aquosos não diferiram estatisticamente.

Tabela 3. Percentual médio de inibição da eclodibilidade de nematódeos gastrintestinais de ovinos ( \pm desvio-padrão) pelos extratos hidroalcoólicos de Eugenia uniflora

\begin{tabular}{cccc}
\hline $\begin{array}{c}\text { Concentração } \\
(\mathbf{m g} / \mathbf{m L})\end{array}$ & $\mathbf{3}$ Extratos Hidroalcoólicos \\
\cline { 2 - 4 } & $\mathbf{E H A} / \mathbf{B M}$ & $\mathbf{E H A} / \mathbf{U S}$ & EHA/MA \\
\hline 40 & $99,75^{\mathrm{Aa}} \pm 0,50$ & $99,71^{\mathrm{Aa}} \pm 0,49$ & $99,73^{\mathrm{Aa}} \pm 0,51$ \\
20 & $97,42^{\mathrm{Aa}} \pm 0,99$ & $99,41^{\mathrm{Aa}} \pm 1,03$ & $99,35^{\mathrm{Aa}} \pm 1,07$ \\
10 & $81,73^{\mathrm{Bb}} \pm 1,81$ & $98,58^{\mathrm{Aa}} \pm 0,83$ & $99,42^{\mathrm{Aa}} \pm 0,57$ \\
5 & $59,26^{\mathrm{Bc}} \pm 6,53$ & $92,52^{\mathrm{Ab}} \pm 2,16$ & $98,21^{\mathrm{Aab}} \pm 0,26$ \\
2,5 & $36,55^{\mathrm{Cd}} \pm 1,57$ & $90,72^{\mathrm{Bb}} \pm 0,95$ & $97,52^{\mathrm{Ab}} \pm 0,67$ \\
1,25 & $20,35^{\mathrm{Ce}} \pm 1,10$ & $88,02^{\mathrm{Bc}} \pm 0,89$ & $97,02^{\mathrm{Ab}} \pm 1,59$ \\
\hline
\end{tabular}

EHA/BM - Extrato hidroalcoólico por banho-maria; EHA/US - Extrato hidroalcoólico por ultrassom; EHA/MA - Extrato hidroalcoólico por maceração.

Letras maiúsculas diferentes, na linha, e letras minúsculas diferentes, na coluna, diferem significativamente $(\mathrm{p} \leq 0,05)$.

Os valores de inibição do extrato aquoso por decocção variaram de 22,04 a $76,04 \%$, sendo que, a partir da concentração de $5 \mathrm{mg} / \mathrm{mL}$, essa atividade permaneceu abaixo de $30 \%$. O extrato aquoso por banho-maria demonstrou menor atividade anti-helmíntica quando comparado aos demais extratos, com $65,39 \%$ de atividade na maior concentração testada $(40 \mathrm{mg} / \mathrm{mL})$. Nas concentrações seguintes, verificou-se diferença significativa nos percentuais de inibição, sendo este efeito diretamente proporcional à concentração $(p \leq 0,05)$. Os dois extratos aquosos não apresentaram resultados semelhantes ao controle com anti-helmíntico, porém, apesar da baixa atividade, todos diferiram do controle com água destilada $(\mathrm{p} \leq 0,05)$. 
O percentual médio de inibição do extrato hidroalcoólico por banho-maria (EHA/BM), na concentração de 20 e $40 \mathrm{mg} / \mathrm{mL}$, foi 97,42 e 99,75\%, respectivamente, não diferindo estatisticamente entre si e do controle com anti-helmíntico $(\mathrm{p}>0,05)$. A partir dessas concentrações, a atividade antihelmíntica apresentou um decréscimo gradual até atingir 20,35\% de inibição na concentração de 1,25 $\mathrm{mg} / \mathrm{mL}$. Os resultados do extrato hidroalcoólico por ultrassom (EHA/US) demonstraram inibição da eclodibilidade superior a $88 \%$ em todas as concentrações testadas. A ação permaneceu acima de $98 \%$ nas concentrações de 10, 20 e $40 \mathrm{mg} / \mathrm{mL}$, as quais não diferiram estatisticamente entre si e nem do controle com anti-helmíntico $(\mathrm{p}>0,05)$. Resultado semelhante foi observado no extrato hidroalcoólico por maceração (EHA/MA), que apresentou atividade de 97,02 a 99,73\%, sendo que todas as concentrações testadas não apresentaram diferença estatística do controle com anti-helmíntico $(\mathrm{p}>0,05)$.

$\mathrm{Na}$ avaliação in vivo, o percentual de redução do OPG variou de 70,29\% a 94,06\% para o grupo controle positivo, sendo que a máxima redução foi sete dias após a administração do anti-helmíntico. Para os grupos tratamento e controle negativo, não foi observada redução na contagem do OPG (Tabela 4). Durante o experimento, todos os animais apresentavam $99 \%$ de infecção por Haemonchus contortus e 1\% por Trichostrongylus spp.

Tabela 4. Média da contagem do $\mathrm{OPG} \pm$ desvio-padrão dos grupos controle positivo (antihelmíntico), tratamento (EHA/MA), controle negativo (água) e porcentagem média de redução do OPG para o grupo controle positivo

\begin{tabular}{|c|c|c|c|c|c|}
\hline Tratamento & D0 & D3 & D7 & D10 & D14 \\
\hline \multicolumn{6}{|c|}{ Controle Positivo } \\
\hline \multirow{2}{*}{ OPG } & $2525^{\mathrm{A}}$ & $750^{\mathrm{B}}$ & $150^{\mathrm{C}}$ & $200^{\mathrm{C}}$ & $525^{\mathrm{B}}$ \\
\hline & $\pm 411,29$ & $\pm 29,09$ & $\pm 57,73$ & $\pm 115,47$ & $\pm 95,74$ \\
\hline \multirow[t]{2}{*}{ \% Redução } & & 70,29 & 94,06 & 92,08 & 79,21 \\
\hline & amento & & & & \\
\hline \multirow{2}{*}{ OPG } & $2425^{\mathrm{A}}$ & $2350^{\mathrm{A}}$ & $2700^{\mathrm{A}}$ & $2500^{\mathrm{A}}$ & $2625^{\mathrm{A}}$ \\
\hline & $\pm 607,59$ & $\pm 704,74$ & $\pm 469,04$ & $\pm 752,77$ & $\pm 512,35$ \\
\hline \multirow[t]{2}{*}{ \% Redução } & & 3,09 & $-11,34$ & $-3,07$ & $-8,25$ \\
\hline & le negativ & & & & \\
\hline \multirow{2}{*}{ OPG } & $2950^{\mathrm{A}}$ & $2925^{\mathrm{A}}$ & $2850^{\mathrm{A}}$ & $3075^{\mathrm{A}}$ & $3175^{\mathrm{A}}$ \\
\hline & $\pm 208,17$ & \pm 150 & $\pm 435,89$ & $\pm 309,57$ & $\pm 499,16$ \\
\hline \% Redução & & 0,85 & 3,39 & $-4,23$ & $-7,63$ \\
\hline
\end{tabular}

Letras maiúsculas diferentes, na linha, diferem significativamente $(\mathrm{p} \leq 0,05)$.

\section{Discussão}

No teste de citotoxicidade, os resultados revelaram ação tóxica de moderada a nula dos extratos aquosos e hidroalcoólicos de E. uniflora nas concentrações testadas. Pesquisas avaliando a toxicidade celular in vitro de E. uniflora são escassas, no entanto, Santos et al. ${ }^{(22)}$, ao avaliarem a citotoxicidade de extrato etanólico de E. uniflora em macrófagos, observaram baixo efeito citotóxico na concentração de $100 \mu \mathrm{g} / \mathrm{mL}$. Outro estudo analisou a citotoxicidade dos frutos da planta Eugenia dysenterica na forma de extrato etanólico e verificou ausência de efeito citotóxico até a concentração de $300 \mu \mathrm{g} /$ $\mathrm{mL}^{(23)}$. O presente estudo apresentou citotoxicidade semelhante aos trabalhos citados anteriormente, visto que na concentração de $250 \mu \mathrm{g} / \mathrm{mL}$ todos os extratos apresentaram o percentual de células 
viáveis, variando de 72,07 a 90,29\%.

Pesquisas acerca da toxicidade in vivo de extrato hidroalcoólico de folhas de E. uniflora realizados em camundongos Balb/C demonstraram ausência de efeitos tóxicos em doses até $4200 \mathrm{mg} / \mathrm{kg}$, quando administrado por via oral, e dose letal $50 \%$ de $220 \mathrm{mg} / \mathrm{kg}$, quando administrado por via intraperitoneal $^{(24)}$. Em outro estudo desenvolvido por Auricchio e Bacchi ${ }^{(25)}$, a dose letal para $50 \%$ das cobaias foi de $5930 \mathrm{mg} / \mathrm{kg}$. Esses trabalhos demonstram a segurança da utilização dos extratos em animais experimentais, pois apresentam valores mais elevados ao utilizado no presente estudo para a realização do teste in vivo.

Os resultados observados no teste in vitro indicam que $E$. uniflora apresenta efeito ovicida diferenciado em Haemonchus contortus, conforme a extração utilizada, visto que, na concentração de $40 \mathrm{mg} / \mathrm{mL}$, o percentual médio de inibição da eclodibilidade foi de 99\% para os extratos EHA/BM, EHA/US e EHA/MA, de $76,04 \%$ para o EA/DEC e $64,99 \%$ para o EA/BM. Esses resultados evidenciam a superioridade da ação anti-helmíntica in vitro dos extratos hidroalcoólicos quando comparados aos aquosos. Essa diferença sugere que os extratos têm componentes ativos diferentes, devido às metodologias utilizadas, mas principalmente devido ao tipo de solvente utilizado, conforme observado na análise fitoquímica.

$\mathrm{Na}$ análise fitoquímica qualitativa, observou-se que todos os extratos tinham na sua composição catequinas, fenóis, saponinas e taninos, porém, apenas os hidroalcoólicos continham antraquinonas, esteroides, flavonoides e triterpenos, confirmando a maior diversidade de compostos com esse tipo de solvente. Estudos compravam que a presença e a maior concentração de compostos como taninos, flavonoides, triterpenos e saponinas têm ação anti-helmíntica ${ }^{(26,27,28,29)}$, sendo que, no presente estudo, apenas os extratos com melhor atividade biológica (EHA/BM e EHA/MA) apresentaram flavonoides e triterpenos na sua composição.

Dentro os compostos encontrados nos extratos avaliados no presente estudo, as saponinas interferem na integridade da membrana dos nematódeos, alterando sua permeabilidade e facilitando a entrada de moléculas por diferença de osmolaridade ${ }^{(30)}$. Os flavonoides têm um mecanismo de ação indireto sobre os helmintos, pois são os principais responsáveis pela atividade antioxidante do vegetal, melhorando a imunidade do hospedeiro e reduzindo o turnover celular, sendo comum plantas com ação medicinal apresentarem altos níveis dessa substância ${ }^{(31)}$. Os taninos têm atividade antiparasitária, devido à redução da taxa metabólica dos nematódeos, diminuindo a disponibilidade de nutrientes ${ }^{(27)}$. Kabasa et al. ${ }^{(32)}$ relatam que esses compostos também podem causar decréscimo da fertilidade e ovipostura das fêmeas adultas. Outro fator importante é a redução na taxa de motilidade das larvas, o que reduz o índice de contaminação da pastagem ${ }^{(33)}$. A ação ovicida observada no presente estudo pode estar relacionada à presença desses compostos, porém, sugere-se que os esteroides, flavonoides e triterpenos obtiveram maior influência, visto que foram encontrados apenas nos extratos com maior percentual de inibição da eclodibilidade.

Estudos científicos avaliando o potencial anti-helmíntico da pitangueira são escassos, entretanto, Furtado $^{(34)}$, ao pesquisar a atividade do extrato hidroalcoólico de E. uniflora na concentração de 108,4 $\mathrm{mg} / \mathrm{mL}$ sobre trichostrongilideos, verificou taxa de inibição da eclodibilidade dos ovos superior a $80 \%$. O presente estudo demonstrou ação semelhante em todos os extratos hidroalcoólicos, porém, essa atividade foi obtida em concentrações cerca de dez vezes inferiores à testada por Furtado ${ }^{(34)}$. Hassum et al. ${ }^{(13)}$, ao avaliarem a ação do extrato hidroalcoólico de E. uniflora na concentração de 200 $\mathrm{mg} / \mathrm{mL}$, observaram uma inibição de $90,5 \%$ no desenvolvimento de larvas do primeiro ao terceiro estágios de nematódeos gastrintestinais, especialmente $H$. contortus e Trichostrongylus spp.. Embora nosso estudo tenha avaliado outra fase de desenvolvimento dos nematódeos, os resultados de inibição 
obtidos foram semelhantes, entretanto, em concentrações muito inferiores (40 mg/mL).

Estudos avaliando o potencial antiparasitário de plantas do gênero Eugenia, como extrato aquoso de E. aquea, demonstraram ação de $65,12 \%$ na inibição da eclodibilidade dos ovos de H. contortus $^{(35)}$, resultados semelhantes aos obtidos com os extratos aquosos do presente estudo, na concentração de $20 \mathrm{mg} / \mathrm{mL}$. Em teste in vivo, Gaspar et al. ${ }^{(36)}$ observaram a redução de $81 \%$ na contagem de ovos por grama de fezes após 14 dias da administração junto à ração de folhas secas de E. dysenteriae e Caryocar brasiliense, na proporção de $1,2 \mathrm{~g} / \mathrm{Kg}$, em ovinos parasitados por H. contortus.

Apesar da eficácia observada no teste in vitro, o extrato hidroalcoólico por maceração de E. uniflora não demonstrou efeito anti-helmíntico no experimento in vivo, nas condições em que foi testado. Diferenças entre os percentuais de eficácia dos testes in vitro e in vivo têm sido registradas, as quais podem ser justificadas pela influência de fatores ambientais e pela metodologia experimental, incluindo dose e período de administração do extrato ${ }^{(37)}$. Além disso, nos testes in vitro, os extratos permanecem em condições ideais em contado direto com o parasito, diferente do que ocorre no teste in vivo ${ }^{(38)}$. A microbiota ruminal pode ser responsável por variações na eficácia dos compostos bioativos, pois pode alterar a estrutura química do componente, o mecanismo de ação de alguns nutrientes, ou medicamentos administrados por via oral ${ }^{(39)}$.

\section{Conclusão}

Os diferentes extratos de Eugenia uniflora inibiram, in vitro, a eclodibilidade de Haemonchus contortus, sendo os extratos hidroalcoólicos as formas mais promissoras. Na marcha fitoquímica, foram observados nos extratos hidroalcoólicos importantes compostos com ação anti-helmíntica, como taninos, flavonoides, triterpenos e saponinas. Quanto à toxidade celular, os resultados sugerem que os extratos têm ação tóxica de moderada a nula nas condições testadas. Os resultados do teste in vivo demonstram que o extrato hidroalcoólico por maceração, na concentração testada, não apresentou eficácia significativa. Assim, os resultados do presente estudo revelaram que os extratos de E. uniflora mostraram-se promissores com ação in vitro, necessitando estudos que avaliem outras concentrações e formas de administração in vivo para obter eficácia na sua administração aos animais.

\section{Referências}

1. Hernández-Villegasa MM, Borges-Argáeza R, Rodriguez-Vivasb RI, Torres-Acostab JFJ, MéndezGonzaleza M, Cáceres-Farfana, M. Ovicidal and larvicidal activity of the crude extracts from Phytolacca icosandra against Haemonchus contortus. Veterinary Parasitology. 2011;179:100-106.

2. Nery PS, Nogueira FA, Martins ER, Duarte ER. Effects of Anacardium humile leaf extracts on the development of gastrointestinal nematode larvae of sheep. Veterinary Parasitology. 2010;171:361-364.

3. Prichard RK. Genetic variability following selection of Haemonchus contortus with anthelmintics. Trends in Parasitology. 2001;17:445-453.

4. Almeida FA, Garcia KCOD, Torgerson, PR, Amarante AFT. Multipleresistance to anthelmintics by Haemonchus contortus and Trichostrongylus colubriformis in sheep in Brazil. Parasitology International. 2010;59:622-625. 
5. Melo ACFL, Bevilaqua CML, Reis IF. Anthelmintic resistance to benzimidazole in gastrointestinal nematodes from small ruminants of semiarid Brazilian northeast. Ciências Animal Brasileira. 2009;10:294-300.

6. Andrade FD, Ribeiro ARC, Medeiros MC, Fonseca SS, Athayde ACR, Ferreira AF, Onaldo GR, Silva WW. Anthelmintic action of the hydroalcoholic extract of the root of Tarenaya spinosa (Jacq.) Raf. for Haemonchus contortus control in sheep. Pesquisa Veterinária Brasileira. 2015;34:942-946.

7. Cabaret J. Pro and cons of targeted selective treatment againstdigestive-tract strongyles of ruminants. Parasite Journal de La Societe Francaise de Parasitologie. 2008;15:506-509.

8. Parra CLC, Olivo CJ, Agnolin CA, Sangioni LA, Buzatti A, Pivoto FL. Garlic (Allium sativum L.) solutions in control of gastrointestinal nematodes in young Holstein cattle. Revista Brasileira de Plantas Medicinais. 2014:16:545-551.

9. Abreu TA, Pinto JRR, Mews HA. Variações na riqueza e na diversidade de espécies arbustivas e arbóreas no período de 14 anos em uma Floresta de Vale, Mato Grosso, Brasil. Rodriguésia - Revista do Jardim Botânico do Rio de Janeiro. 2014;65:73-88.

10. Consolini AE, Sarubbio M. Pharmacological effects of Eugenia uniflora L. (Myrtaceae) aqueous extract on rat's heart. Journal of Ethnopharmacology. 2002;81:57-63.

11. Adebajo AC, Oloki KJ, Aladesanmi A. Antimicrobial activity of the leaf extract of Eugenia uniflora. Phytotherapy Research. 1989;3:258-259.

12. Schapoval EES, Silveira SM, Miranda ML, Alice CB, Henriques AT. Evaluation of some pharmacological activities of Eugenia uniflora. Journal of Ethnopharmacology. 1994;44:137-142.

13. Hassum IC, Venturi CR, Gosmann G, Deiro AMG. Ação dos extratos de quatro plantas sobre larvas infectantes de nematódeos gastrintestinais de ovinos. Revista Cubana de Plantas Medicinales. 2013;18:278287.

14. Matos FJA. Farmácias vivas. 3 ed. Fortaleza: Edições UFC; 1998. 220p.

15. Mosmann T. Rapid colorimetric assay for cellular growth and survival: application to proliferation and cytotoxicity assays. Journal of Immunological Methods. 1983;65:55-63.

16. Gordon HM, Whitlock HV. A new technique for counting nematode eggs in sheep faeces. Journal of the Council for Scientific and Industrial Research. 1939;12:50-52.

17. Hubert J, Kerboeuf DA. Microlarval development assay for the detection of anthelmintic resistance in sheep nematodes. Veterinary Research. 2003;130:442-446.

18. Roberts FHS, O'Sullivan SP. Methods for egg counts and larvae cultures for strongyles infesting the gastrointestinal tract of cattle. Australian Journal of Agricultural Research. 1950;1:99-102.

19. Coles GC, Bauer C, Borgsteede FHM, Geerts S, Klei TR, Taylor MA, Waller PJ. World Association for the advancement of Veterinary Parasitology (W.A.A.V.P.) methods for detection of anthelmintic resistance in nematodes of veterinary importance. Veterinary Parasitology. 1992;44:35-44.

20. Camurça-Vasconcelos ALF, Bevilaqua CML, Morais SM, Maciel MV, Costa CTC, Macedo ITF, Oliveira LMB, Braga RR, Silva RA, Vieira LS. Anthelmintic activity of Croton zehntneri and Lippia sidoid esessential oils. Veterinary Parasitology. 2007;148:288-294.

21. Amorim ACL, Lima CKF, Hovell AMC, Miranda ALP, Rezende CM. Antinociceptive and hypothermic evaluation of the leaf essential oil and isolated terpenoids from Eugenia uniflora L. (Brazilian pitanga). Phytomedicine. 2009;16:923-928. 
22. Santos KKA, Matias EFF, Tintino SR, Souza CES, Braga MBBM, Guedes GMM, Rolón M, Veja C, Arias AR, Costa JGM, Menezes IRA, Coutinho HDM. Anti-Trypanosoma cruzi and cytotoxic activities of Eugenia uniflora L. Experimental Parasitology. 2012;131:130-132.

23. Roesler R, Lorencini M, Pastore G. Brazilian cerrado antioxidante sources: cytotoxicity and phototoxicity in vitro. Ciência e Tecnologia de Alimentos. 2010;30:814-821.

24. Schmeda-Hirschmann G, Theod Ulo ZC, Franco L, Ferro E. Preliminary pharmacological studies on Eugenia uniflora leaves: xanthine oxidase inhibitory activity. Journal of Ethnopharmacology. 1987;21:183186.

25. Auricchio MT, Bacchi EM. Folhas de Eugenia uniflora L. (pitanga): Revisão. Revista do Instituto Adolfo Lutz. 2003;62:55-61.

26. Girme AS, Bhalke RD, Ghogare PB, Tambe VD, Jadhav RS, Nirmal SA. Comparative in vitro anthelmintic activity of Mentha piperita and Lantana camara from Western India. Dhaka University Journal of Pharmaceutical Sciences. 2006;5(1):5-7.

27. Hoste H, Jackson F, Athanasiadou S, Thamsborg SM, Hoskin SO. The effects of tannin-rich plants on parasitic nematodes in ruminants. Trends in Parasitology. 2006;22:253-261.

28. Roy H, Chakraborty A, Bhanja S, Nayak BS, Mishra SR, Ellaiah P. Preliminary phytochemical investigation and anthelmintic activity of Acanthospermum hispidum DC. Journal of Pharmaceutical Science and Technology. 2010;2(5):217-221.

29. Wang GX, Han J, Zhao LW, Jiang DX, Liu YT, Liu XL. Anthelmintic activity of steroidal saponins from Paris polyphylla. Phytomedicine. 2010;17(14):1102-1105.

30. Ademola IO, Fagbemi BO, Idowu SO. Anthelmintic activity of extracts of Spondias mombin against gastrointestinal nematodes of sheep: studies in vitro and in vivo. Tropical Animal Health and Production. 2005;37(3):223-235.

31. Menezes H. Imunidade inata e específica em plantas. Semina: Ciências Biológicas e da Saúde. 2009:30(2):195-212.

32. Kabasa JD, Opuda-Asibo J, Ter Meulen U. The effect of oral administration of polyethylene glycol on faecal helminth egg counts in pregnant goats grazed on browse containing condensed tannins. Tropical Animal Health and Production. 2000;32(2):73-86.

33. Molan AL, Duncan AJ, Barry TN, Mcnabb WC. Effects of condensed tannins; and crude sesquiterpene lactones extracted from chicory on the motility of larvae of deer lungworm and gastrointestinal nematodes. Parasitology. 2003;52:209-218.

34. Furtado KS. 2006. Alternativas fitoterápicas para o controle da verminose ovina no estado do Paraná: testes in vitro e in vivo. Tese, Universidade Federal do Paraná, Brasil, 147f. Disponível em: http://www.oikos.ufpr.br/ publicacoes/teses/01_Tese\%20Silvana\%20Furtado.pdf

35. Daryatmo J, Hartadi H, Orskov ER, Adiwimarta K, Nurcahyo W. In vitro screening of various forages for anthelmintic activity on Haemonchus contortus egg. Advances in Animal Biosciences. 2010;1:113-113.

36. Gaspar AT, Henrique RG, Araujo AH, Aguiar FGL, Zilis T, Silva BV, Barros ELE, Oliveira QML, Molica ME, Melo RF. Haemonchus contortus: in vivo anthelmintic activity of Eugenia dysenterica DC and Caryocar brasiliense Cambes sleaves in sheep. Planta Medica. 2010;76:636-636.

37. Martin M, Mcorkle CM, Mathias E. 2001. Ethnoveterinary Medicine: An annotated bibliography of community animal healthcare. ITDG Publishing, London,1379-1384, 2001. 
38. Peneluc T, Domingues LF, Almeida GN, Ayre MCC, Moreira ELT, Cruz ACF, Bittencourt TCBS, Almeida MAO, Batatinha MJM. Atividade anti-helmíntica do extrato aquoso das folhas de Zanthoxylum rhoifolium Lam. (Rutaceae). Revista Brasileira de Parasitologia Veterinária. 2009;18:43-48.

39. Vandamme THF, Ellis KJ. Issues and challenges in developing ruminal drug delivery systems. Advanced Drug Delivery Reviews. 2004;56:1415-1436. 